\title{
Microstructural Analysis of Ti/W/WC Deposition by ESD Method
}

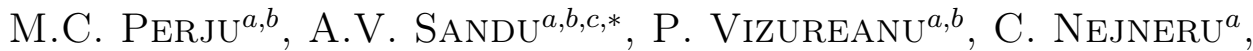 \\ C.A. Tugui ${ }^{a}$ AND D.D. Burduhos-Nergis ${ }^{a}$ \\ ${ }^{a}$ Gheorghe Asachi Technical University of Iasi, Faculty of Materials Science and Engineering, \\ Blvd. D. Mangeron 41, 700050, Iaşi, Romania \\ ${ }^{b}$ Center of Excellence Geopolymer \& Green Technology (CEGeoGTech), \\ School of Materials Engineering, Universiti Malaysia Perlis, 01000 Kangar, Perlis, Malaysia \\ ${ }^{c}$ Romanian Inventors Forum, Sf. P. Movila 3, Iaşi, Romania
}

Doi: 10.12693/APhysPolA.138.214

*e-mail: sav@tuiasi.ro

\begin{abstract}
The paper proposes an increase in wear resistance of $\mathrm{Fe}-\mathrm{C}$ alloy parts by coating with thin layers to assure special properties, using inexpensive support materials subjected to deposition of the expensive materials. The effect is to improve the tribological qualities of the parts working in harsh conditions of temperature and pressure and also with sands the aggressive corrosion environments, in which roughness is not an impediment to the smooth functioning of the subassembly. The paper will study the layersubstrate subassembly for various types of depositions, whose compatibility with the substrate provide high quality parts. Thus, this system of layers can be applied both on the new and worn parts, been able to recondition and reintroduce in an intensive exploitation regime any parts with complex configuration operating in dynamic conditions. By means of the Elitron 22A installation, thin layer deposits were made to modify the surface properties of the base material (ferrito-perlitic cast iron), using for multilayer layer deposition: triple layer, type: $\mathrm{Ti} / \mathrm{W} / \mathrm{WC}$. The investigation of the samples deposited by the electrospark deposition method was carried out using a scanning electron microscope).
\end{abstract}

topics: electrospark deposition, wear resistance, coatings, SEM

\section{Introduction}

In recent years, a number of modern materials have been developed around the world exhibiting unique properties $[1,2]$. In recent years, worldwide has developed a range of metallic depositions that provide optimal solutions for various problems of wear, corrosion and hardness encountered in industry. These depositions are called in some research pelliculary or thin films $[3,4]$.

Along with traditional technologies of coatings achievement we assist to the development, improvement and extension of some modern coating methods, through physical and physical-chemical methods, which assure high purity and adherence through a very large variety of coating realizing procedures [5-9].

One method of deposition is pulsed electrical discharge method, which is a topical research method, the method being used to cover by deposition of the installations components which works in heavy abrasive wear wet and dry layers in order to obtain superior tribological surface qualities, but also for reconditioning metal parts [10-12].

Experimentally it was found that pulsed electrical discharge method is able to provide relevant information with a high degree of certainty and also cost effective [13]. The essence lies in the complexity of filing physical phenomena that occur during the technological process [14]. The potential to significantly influence the content is the results obtained from the analysis and substantiation physicochemical phenomena that occur in the superficial layers closely related to technologies for obtaining these layers [15]. For part of the analyzed researches, surface treatments were made [16] on hard cast iron parts with application in the automotive industry.

\section{Experimental part}

In this study the optimum amplitude and cycle parameters have been used in order to modify the surface properties of the base material (cast iron) by coating its surface with thin layers, by means of Elitron 22A equipment [17]. Therefore, in order to combine the advantages of the surface coatings, multilayer deposits have been considered, using three types of electrodes. In this study, titanium electrodes [18], tungsten and tungsten carbide $[19,20]$ have been used to create a triple layer deposition on the ferrito-perlitic cast iron [12]. The obtained layers morphology $[21,22]$ has been analyzed by means of an SEM microscope in order to highlight the final layer quality [23-26]. 


\section{Results and discussions}

Titanium was used for the first layer in order to create a high compact interface with a low number of cracks. Moreover, due to these properties, this layer is compatible with further layers deposition which must ensure high hardness and corrosion resistance. As can be seen in the scanning electron microscopy (SEM) micrographs (Fig. 1) the deposited layer does not present drops, but a relatively compact surface.

Therefore, the Ti elemental mapping confirms the melting and mixing behavior of the first layer during further depositions. This element presents a high content and uniform distribution on the sample surface.

Furthermore, the $\mathrm{W}$ and $\mathrm{WC}$ depositions present similar characteristics in terms of concentration (Table I) and surface distribution.

For the second layer, tungsten was selected due to its good adherence to the titanium layer surface. The Ti layer possesses especially high hardness, yet multiple cracks appear.

The following layer, the third, must be compatible with the tungsten layer and it must contain, if possible, hard intermetallic compounds. Moreover, these compounds must increase the hardness of the deposited layer, even if the previous layer has been melted and solidified for twice. Therefore, the tungsten-carbide electrode was chosen, due to the fact that a homogeneous coating with high hardness can be obtained.

There are multiple methods that can be used for the measurement of the deposited layer. Still, by means of elemental mapping and morphological analysis in different points, the thickness of the $\mathrm{Ti}$, $\mathrm{W}$ and $\mathrm{WC}$ multilayer can be measured.

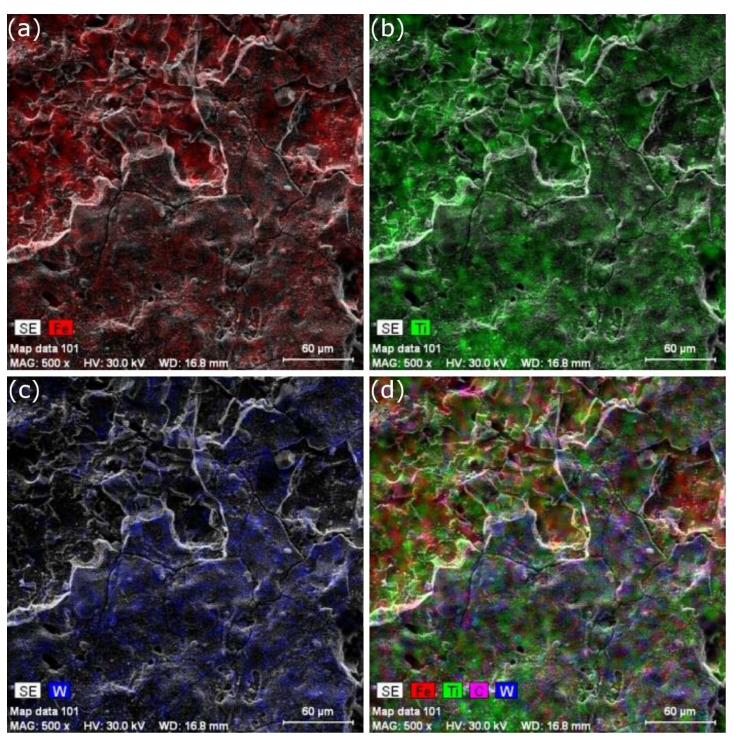

Fig. 1. Deposited layer elemental mapping of (a) Fe, (b) Ti, (c) W, (d) Fe, Ti, C, W.
TABLE I

Elemental chemical composition of $\mathrm{Ti} / \mathrm{W} / \mathrm{WC}$ layer

\begin{tabular}{c|c|c|c|c}
\hline \hline Element & $\mathrm{Fe}$ & $\mathrm{C}$ & $\mathrm{W}$ & $\mathrm{Ti}$ \\
\hline wt\% & 29.66 & 14.79 & 31.27 & 24.28
\end{tabular}

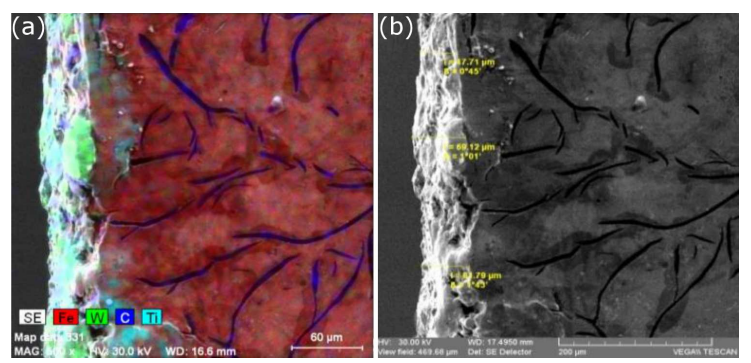

Fig. 2. Deposited layer thickness measurement: (a) Fe, W, C, Ti elemental mapping, (b) layer thickness variation.

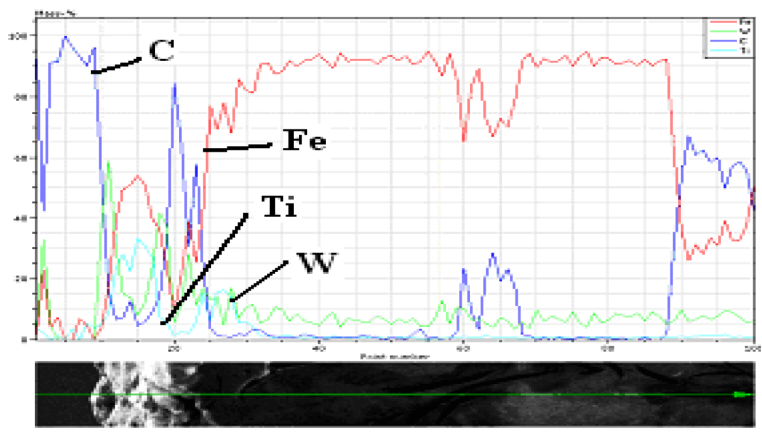

Fig. 3. EDS line scan analysis in weight percentage.

According to Fig. 2 the layer thickness varies between $47.71 \mu \mathrm{m}$ and $69.12 \mu \mathrm{m}$ presenting a relatively constant value, especially for this type of deposition. Therefore, the second and the third deposition increase the layer thickness uniformity and smoothness.

The titanium is mainly concentrated in the edge areas of the surface, presenting relatively compact islands. Also, in the thickness elemental mapping of the deposited layer multiple well-defined tungsten areas can be observed, yet the tungsten carbides present an uneven distribution over the titanium layer.

Moreover, Fig. 2a highlights the layer morphology and the presence of $\mathrm{Ti}$ spherical microdrops. The presence of tungsten carbide is confirmed by the appearance of relatively uniform carbon areas all over the surface (analyzed on the layer thickness, i.e. in depth).

Therefore, the WC melts and the previously deposited layers create a uniformity in the layer, which increases the surface quality.

By means of EDS line scan analysis (Fig. 3) the presence of carbon in a percentage of $90 \div 100 \%$ 


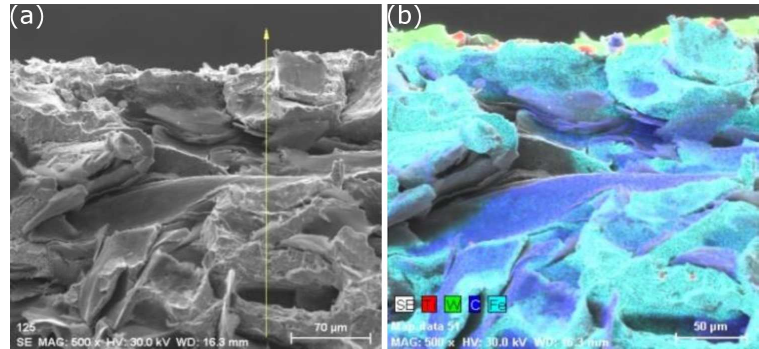

Fig. 4. (a) Fracture EDS scan analysis of $\mathrm{Ti} / \mathrm{W} / \mathrm{WC}$ deposited layer, (b) Ti, W, C, Fe elemental mapping.

on the surface and in depth confirms the uniform distribution and penetration of tungsten carbides in the deposited layers.

When the line scan analysis is performed by weight, the presence of tungsten and carbon in high quantity on the surface and close to it is revealed, while high concentrations of titanium are confirmed close to the cast iron surface.

The deposited triple layer shows a high homogeneity and adhesion, with slight spreading and exfoliation, with high hardness (brittle fracture type) and amorphous characteristics (lack of visible granulation), Fig. 4.

The titanium as the first deposited layer on the ferrito-perlitic cast iron surface creates a uniform intermediate layer well embedded to the surface by microalloys. The aim of the second deposition, tungsten deposition, is the redissolution of the titanium layer on the ferrito-perlitic substrate due to the high heating, while the tungsten deposition on the surface is just accidental.

Subsequently, the third layer of tungsten carbide is deposited which melts the surface of the previous layers.

\section{Conclusions}

If the main objective is to improve the wear resistance through hard layer deposition, it is necessary to use a multilayer deposition, where the first layer should be the high adherence interface between the substrate and the sequent layer with the imposed properties, i.e. high hardness.

In the case of multiple layers, the discharge parameters are adjusted due to the modification of the substrate physico-chemical characteristics such as conductivity, diffusivity, electrical resistance, melting point, and vaporization temperature.

According to the morphology characterization, the Ti layer presents a smoother surface compared to $\mathrm{W}$ and $\mathrm{WC}$ deposition layers.

However, in the case of the multilayer characterization, the surface is uniform without ripping the material. That is because the Ti layer interface gives good compactness and adherence, while the $\mathrm{W}$ and WC layers create a hard surface by means of tungsten carbides and eliminate the Ti deposition related defects (oxides, pore, cracks).

\section{References}

[1] B. Jez, M. Nabiałek, K. Jez, Materiale Plastice 56, 1008 (2019).

[2] J. Zbroszczyk, J. Olszewski, W. Ciurzyńska, M. Nabiałek, P. Pawlik, M. Hasiak, A. Łukiewska, K. Perduta, J. Magn. Magn. Mater. 304, e724 (2006).

[3] I. Pliszka, N. Radeka, Proced. Eng. 192, 707 (2017).

[4] M.C. Perju, P. Vizureanu, Rev. Chim. (Bucharest) 65, 694 (2014).

[5] Y. Xie, M. Wang, Surf. Coat. Technol. 201, 691 (2006).

[6] Z. Chen, Y. Zhou, Surf. Coat. Technol. 201, 1503 (2006).

[7] Z. Chen, Y. Zhou, Surf. Coat. Technol. 201, 2419 (2006).

[8] J.H. Abboud, K.Y. Benyounis, A.G. Olabi, M.S.J. Hashmi, J. Mater. Process. Technol. 182, 427 (2007).

[9] S. Imamura, H. Fukui, A. Shibata, N. Omori, M. Setoyama, Surf. Coat. Technol. 202, 820 (2007).

[10] S. Frangini, A. Masci, Surf. Coat. Technol. 204, 2613 (2010).

[11] T.J. Lesinjak, J. Tusiek, Sci. Technol. Weld. Join. 7, 391 (2002).

[12] Z. Jiao, S. Peterkin, L. Felix, R. Liang, J.P. Oliveira, N. Schell, N. Scotchmer, E. Toyserkani, Y. Zhou, J. Mater. Eng. Perform. 27, 4799 (2018).

[13] B. Shahul, M. Cijo, K.G. Sunny, Int. J. Innovat. Res. Adv. Eng. 1, 106 (2014).

[14] P. Vizureanu, M.C. Perju, D.C. Achiţei, C. Nejneru, Advanced Electro-Spark Deposition Process on Metallic Alloys, in: Advanced Surface Engineering Research, Ed. M.A. Chowdhury, Intech, 2018.

[15] Z. Mahim, M.A.A. MohdSalleh, N. Saud, Europ. J. Mater. Sci. Eng. 4, 37 (2019).

[16] S. Dolinšek, J. Tušek, Z. Kampuš, in: Proc. 12th Int. Sci. Conf. Achievements in Mechanical and Materials Engineering, Gliwice-Zakopane 2003, Elsevier, Amsterdam 2003, p. 1103.

[17] Instalaţie Elitron 22, Academia de Ştiinţe, Republica Moldova, Chişinău, 1992.

[18] M.C. Perju, P. Vizureanu, C. Nejneru, A.E. Lărgeanu, in: Proc. XIIth Int. Conf. Sci. Papers "Scientific Research and Education in the Air Force" (AFASES), Braşov (Romania) 2010 p. 912.

[19] M.C. Perju, C. Nejneru, A.E. Lărgeanu, D.C. Achiţei, R.G. Ştefanică, in: Proc. 15th Int. Conf. Modern Technologies, Quality and Innovation, Vol. II, 2011, p. 845 . 
[20] T. Miller, L. Pirolli, F. Deng, C. Ni, A.V. Teplyakov, Surf. Coat. Technol. 258, 814 (2014).

[21] L. Suttey, V. Sudhakar, Europ. J. Mater. Sci. Eng. 3, 203 (2018).

[22] M.G. Minciuna, P. Vizureanu, V. Geanta, I. Voiculescu, A.V. Sandu, D.C. Achitei, A.M. Vitalariu, Rev. Chim. (Bucharest) 66, 891 (2015).

[23] A.V. Sandu, A. Ciomaga, G. Nemtoi, C. Bejinariu, I. Sandu, Microsc. Res. Techn. 75, 1711 (2012).
[24] C. Paraschiv, I. Stirbu, R. Cimpoesu, M. Bernevig, C. Nejneru, V. Manole, N. Cimpoesu, G. Zegan, Optoelectron. Adv. Mater. Rapid Commun. 10, 87 (2016).

[25] E. Chirila, M. Susan, B.L. Gavrila, A.V. Sandu, Rev. Chim. (Bucharest) 64, 482 (2013).

[26] D. Liu , W. Gao, Z. Li, H. Zhang, Z. Hu, Mater. Lett. 61, 165 (2007). 